\title{
A case-control study on the effect of metabolic gene polymorphisms, nutrition, and their interaction on the risk of non-alcoholic fatty liver disease
}

\author{
Luca Miele - Valentina Dall'Armi $\cdot$ Consuelo Cefalo $\cdot$ Bojan Nedovic \\ Dario Arzani - Rosarita Amore - Gianlodovico Rapaccini - Antonio Gasbarrini • \\ Walter Ricciardi • Antonio Grieco • Stefania Boccia
}

Received: 28 June 2013/ Accepted: 28 December 2013/Published online: 9 January 2014

(c) Springer-Verlag Berlin Heidelberg 2014

\begin{abstract}
The oxidative stress is a key issue in the etiology of non-alcoholic fatty liver disease (NAFLD). The aim of our study was to evaluate the effect of metabolic gene polymorphisms involved in the oxidative stress (GSTT1, GSTM1, SULT1A1, CYP2E1, and 1A1), lifestyle and nutrition aspects, and their interaction, on the risk of NAFLD. We enrolled 294 cases and 359 controls, and collected demographics, anthropometric, lifestyle, and nutrition data. A subgroup of NAFLD provided additional data on nutrients and on physical activity engagement. Each patient provided a blood sample for DNA extraction and genotyping. Clinical and laboratory data were collected from cases. Multivariable analysis shows a significant protective effect of age, gender, and moderate drinking habits on the risk of NAFLD, while an increased risk for greater consumption of fruit and grilled meat or fish. Significant interactions were reported between alcohol
\end{abstract}

Valentina Dall'Armi and Consuelo Cefalo have contributed equally. Antonio Grieco and Stefania Boccia have shared senior authorship.

L. Miele · C. Cefalo · G. Rapaccini - A. Gasbarrini · A. Grieco Institute of Internal Medicine, Università Cattolica del Sacro Cuore, Rome, Italy

L. Miele · G. Rapaccini

Internal Medicine and Gastroenterology Unit, Complesso

Integrato Columbus, Rome, Italy

V. Dall'Armi - S. Boccia

Clinical and Molecular Epidemiology, Area of Systems

Approaches and Non Communicable Diseases, IRCCS San

Raffaele Pisana, Rome, Italy

B. Nedovic · D. Arzani - R. Amore - W. Ricciardi .

S. Boccia $(\square)$

Section of Hygiene, Institute of Public Health, Università Cattolica del Sacro Cuore, L.go F. Vito, 00168 Rome, Italy

e-mail: sboccia@rm.unicatt.it consumption, fruit intake, grilled meat and fish, and selected genetic variants. From the subgroup analysis, a moderate/high consumption of fat and/or grilled meat/fish, and a high consumption of white meat increase the risk of NAFLD. Engaging any physical activity at least 1 time/ week halves the risk of NAFLD. Besides confirming the beneficial effect of moderate alcohol intake and regular physical activity, and the increased risk associated with high fruit and fat intake, for the first time, we report a detrimental effect of grilled food on NAFLD risk. An effect modification by selected gene variants increases the risk in combination with fruit and grilled food intake.

Keywords Non-alcoholic fatty liver disease $\cdot$ Metabolic genes · Polymorphism · Nutrition · Gene-environment interaction

\section{Introduction}

Non-alcoholic fatty liver disease (NAFLD) is currently the most common cause of transaminases elevation in Western countries, where it has been recognized as a major public health burden (Loomba and Sanyal 2013). NAFLD is considered as the hepatic side of metabolic syndrome and is extremely common in subjects with visceral obesity, type 2 diabetes mellitus, dyslipidemia, or insulin resistance (Chalasani et al. 2012). Evidences of high prevalence and incidence of NAFLD in the general population require joint efforts to identify the modifiable risk factors for the disease prevention.

The onset of non-alcoholic steatohepatitis (NASH) on a background of fatty liver is believed to be due to an interplay between genetic and environmental factors, with a major role played by the oxidative stress (Sumida et al. 
2013). The "multiple parallel hit" has recently replaced the classical "two-hit" theory to explain the liver injury, even though the mechanisms involved in the pathogenesis of NAFLD are not yet clarified (Hijona et al. 2010; Tilg and Moschen 2010; Miele et al. 2005). As the natural course of NAFLD and its progression to NASH is highly variable even with the same risk factors, it is reasonable that single nucleotide polymorphisms (SNPs) in genes potentially involved in oxidative stress could play a role in the disease onset and progression as reported by recent studies (Hashemi et al. 2012; Hori et al. 2009; Hardwick et al. 2013; Bell et al. 2011; Fisher et al. 2009). A meta-analysis pointed out at the role of Patatin-like phospholipase domain-containing protein 3 gene to confer either increased risk of NAFLD or its progression (Sookoian and Pirola 2011). Among the lifestyle factors, poor dietary habits and lack of physical activity engagement have been recently reported as risk factors for NAFLD onset (Loomba and Sanyal 2013). High carbohydrate and fructose consumption, as well as high red meat and low fish intake, have been associated with an increased risk of NAFLD and overall inflammation at liver biopsy (Solga et al. 2004; Zelber-Sagi et al. 2011; Tappy and Le 2012). Few reports, however, have examined the interaction between nutritional factors and genes involved in the oxidative stress in the pathogenesis of NAFLD so far (Bell et al. 2011; Daly et al. 2011; Hardwick et al. 2013). This might lead to identification of subjects at higher risk of NAFLD progression to NASH, thus suggesting a potential target of subjects that might benefit from tailored prevention programs.

The aim of our hospital-based case-control study was to evaluate the effect of selected polymorphisms in glutathione $S$-transferase (GSTM1, GSTT1), sulfotransferase (SULT1A1), and cytochrome (CYP2E1 and 1Al) genes, their mutual combination, and their interaction with nutritional factors on the risk of NAFLD. In a subgroup of patients with information on additional nutritional factors and recreational physical activity assessment, we also assessed the association between these variables and the risk of NAFLD.

\section{Materials and methods}

\section{Study population}

Study participants were recruited among patients admitted to the teaching hospital "Agostino Gemelli" of the Università Cattolica del Sacro Cuore (Rome, Italy) from January 2005 until July 2011, and eligibility was restricted to Caucasian individuals born in Italy. Cases were recruited among subjects referred to the Outpatient Liver Unit of the hospital (De Feo et al. 2012). According to the current recommendations (Loria et al. 2010), the diagnosis of NAFLD was based on the presence of sonographic features of hepatic steatosis based on the presence of the bright liver pattern as recommended by the American Gastroenterology Association (Sanyal 2002) and the absence of all the following factors: significant ethanol intake $(>20 \mathrm{~g} /$ day for females and $>30 \mathrm{~g} /$ day for males); drug-induced liver disease within the last 5 years; autoimmune liver disease (manifested by positive serum antinuclear, liver/kidney microsomal, mitochondrial, smooth-muscle, and/or neutrophil cytoplasmic antibody titers); seropositivity for hepatitis $\mathrm{B}$ (HBs-Ag) or $\mathrm{C}$ infection and autoantibodies (anti-HCV IgG); fasting transferrin saturation $>45 \%$; low serum alpha1-antitrypsin levels; and ceruloplasmin levels indicative of Wilson's disease. Ultrasound determinations were performed by the same identical operator (GR) during the entire study period.

The control group was selected among patients without steatosis admitted to the same hospital during the same time period with a broad range of diagnoses without fatty liver and metabolic disease and no alcohol abuse. In closer details, around $50 \%$ of our control population were blood donors and the remaining were patients undergoing surgical interventions (laparoscopic cholecystectomy, appendicitis, inguinal hernia) and patients affected by chronic disease as hypertension, or chronic obstructive pulmonary disease undergoing routine physical examinations.

With a response rate of 98 and $93 \%$, respectively, for cases and controls, we finally recruited 294 NAFLD cases and 359 controls. Written informed consent was obtained from all study subjects. All procedures followed were in accordance with the ethical standards of the responsible committee on human experimentation (institutional and national) and with the Helsinki Declaration. Informed consent was obtained from all patients for being included in the study.

Data collection

\section{Demographics, anthropometric, clinical and laboratory data}

Information on age and gender was collected from the study participants. Cases and controls underwent anthropometric investigation, with height $(\mathrm{m})$ and weight $(\mathrm{kg})$ taken at the recruitment day. Clinical and laboratory data were collected only from NAFLD patients. Waist circumference was measured in a standing position at the level of the umbilicus. The presence of diabetes mellitus (fasting glucose level $>7.1 \mathrm{mmol} / 1$ or treatment with antidiabetic drugs) and hypertension (blood pressure $>130 / 85 \mathrm{~mm} \mathrm{Hg}$ or current treatment for hypertension) were recorded. The laboratory evaluation included liver biochemistry, blood count, total and high-density lipoprotein cholesterol and 
total triglyceride level, fasting glucose, and insulin level. Definition of hypercholesterolemia was performed according the third Report of the Expert Panel on Detection, Evaluation, and Treatment of High Blood Cholesterol in Adults (Adult Treatment Panel III, or ATP III) presents the National Cholesterol Education Program (NCEP) (http://www.nhlbi.nih.gov/guidelines/cholesterol/atp3full. pdf). The degree of insulin resistance was determined by the homeostatic model assessment (Matthews et al. 1985).

\section{Lifestyle and nutrition data}

Cases and controls were interviewed by trained physicians using a structured questionnaire to collect information on lifestyle habits including smoking and drinking history, fruit and grilled meat or fish intake, and salt addition to meals. The response rate for interview completion was 94.8\% among cases and $93.8 \%$ among controls.

In a subgroup $(N=280)$ of NAFLD patients $(N=82)$ and controls $(N=198)$, information were retrieved using an additional questionnaire detailing on specific nutrients, namely fresh vegetables, pulses, red meat, processed meat, white meat and fish consumption, and recreational physical activity (walking, competitive sport, housework, gardening, cycling, and gymnastics).

Questions about lifestyle habits all focused on the time period ending 1 year prior to diagnosis for cases and on the year prior to the interview date for controls.

\section{DNA extraction and genotyping}

DNA was extracted from the peripheral blood lymphocytes of each participating subject. GSTM1 and GSTT1 null alleles were identified using a multiplex polymerase chain reaction (PCR)-based method (Arand et al. 1996). The polymorphic site at nucleotide 638 in exon 7 (Arg213His (*2 allele), rs9282861) of the SULT1A1 gene was genotyped by PCR-restriction fragment length polymorphisms (RFLP) analysis as described by Coughtrie et al. (Coughtrie et al. 1999), CYPIA1 3'-flanking region MspI polymorphism (CYP1A1*2A allele, rs4646903), CYP2E1 Pst I polymorphism [CYP2E1*5B allele, rs3813867 (PstI)] and CYP2E1 DraI ( $* 5 A$ or $* 6$ alleles, rs6413432) were also determined by PCR-RFLP analyses. Quality control for each genotyping was performed in each experiment, and $10 \%$ of the total samples were randomly selected and reanalyzed with $100 \%$ concordance. All laboratory procedures were carried out blind to case-control status.

\section{Statistical methods}

The body mass index (BMI) was calculated as the weight divided by the height squared [weight $(\mathrm{kg}) /$ height $(\mathrm{m})^{2}$ ].
Demographic characteristics, lifestyle, and the genetic polymorphisms of the two groups were compared by means of univariate and bivariate statistical tests. In particular, the Pearson's Chi-square test for categorical variables (or Fisher's Exact test for expected cell frequencies $<5$ ) and the Student's $t$ test for continuous variables were used.

A logistic regression analysis was implemented to assess the risk of NAFLD. Odds ratio (OR) and $95 \%$ confidence intervals (CI) were calculated. The factors associated with the disease were selected in a forward-stepwise fashion, via the likelihood ratio test. Two-way interactions between the variables of the so derived statistical model and the candidate genes, and two-way gene-gene interactions, were fitted.

A logistic regression analysis was also implemented to assess the risk of NAFLD in the subgroup of 280 subjects with the aim of exploring the role of dietary patterns and physical activity. Strongly associated variables were combined in class variables taking into account the estimated pure effect of each variables when assigning the order of the classes (see results section). The association between pairs of variables was formerly tested with the Chi-square test (or Fisher's exact test for cell frequencies $<5$ ); subsequently, the pure effect of each variable was estimated by fitting a simple logistic regression.

Hardy-Weinberg equilibrium (HWE) was verified for all candidate genes using the tool accessible at the following website: http://ihg.gsf.de/cgi-bin/hw/hwa1.pl. The low frequency of subjects with double mutation $(<7 \%$ for all genes) suggested the use of a dominant model for all genes (Cordell and Clayton 2005). Statistical significance was set at the $5 \%$ level. Statistical analyses were implemented in STATA/SE V10 (Stata Corporation, College 162 Station, TX).

\section{Results}

Our study included 653 subjects, comprising 294 cases and 359 controls. Table 1 reports the clinical features of NAFLDs, with $34 \%$ of cases being obese and $14 \%$ diabetics. Around $45 \%$ of patients had hypercholesterolemia and $22 \%$ had metabolic syndrome (MS). Table 2 details demographic and anthropometric data, together with lifestyle factors and genetic polymorphisms in the entire population. Mean age was lower among cases than controls $(p<0.001)$, while BMI was higher in cases than controls ( $p=0.008)$. Gender, smoking, and drinking habits were balanced across the groups, with 30-40\% females, around $55 \%$ of never smokers, and approximately $50 \%$ of never drinkers (Table 2).With the exception of SULT1A1 $(p=0.017)$, we did not observe significant differences in distribution of the studied SNPs (Table 2). From the 
Table 1 Clinical features of 234 cases with non-alcoholic fatty liver disease (NAFLD)

\begin{tabular}{|c|c|}
\hline Clinical parameters & Cases $\left(\right.$ mean $\left.\pm \mathrm{SD}^{\mathrm{a}}\right)$ \\
\hline Weight (kg) & $84.11 \pm 16.96$ \\
\hline Height (m) & $1.70 \pm 0.09$ \\
\hline Waist length $(\mathrm{cm})$ & $100.87 \pm 11.44$ \\
\hline Obesity $\left(\right.$ BMI $\left.>30 \mathrm{~kg} / \mathrm{m}^{2}\right)$ & $98(34 \%)$ \\
\hline Diabetes $[n(\%)]$ & $41(14 \%)$ \\
\hline Hypertension $[n(\%)]$ & $93(32 \%)$ \\
\hline Glucose level (mg/dl) & $97.73 \pm 32.43$ \\
\hline Fasting insulin level $(\mathrm{mmol} / \mathrm{l})$ & $15.85 \pm 10.87$ \\
\hline HOMA score & $3.88 \pm 3.34$ \\
\hline HOMA score $>2.5[n(\%)]$ & $117(40 \%)$ \\
\hline Total cholesterol (mg/dl) & $196.25 \pm 47.18$ \\
\hline HDL (mg/dl) & $46.96 \pm 11.51$ \\
\hline Hypercholesterolemia $[n(\%)]$ & $124(43 \%)$ \\
\hline Triglyceride level (mg/dl) & $145.68 \pm 82.94$ \\
\hline Hypertriglyceridemia $[n(\%)]$ & $101(35 \%)$ \\
\hline MS ATP III ${ }^{\mathrm{b}}[n(\%)]$ & $64(22 \%)$ \\
\hline AST (IU/l) & $38.65 \pm 33.49$ \\
\hline ALT (IU/l) & $55.91 \pm 40.58$ \\
\hline AST/ALT ratio & $0.85 \pm 0.68$ \\
\hline AST/ALT ratio $\geq 1.0[n(\%)]$ & $48(17 \%)$ \\
\hline GGT (IU/l) & $67.33 \pm 88.06$ \\
\hline Alkaline phosphatase (IU/l) & $174.58 \pm 83.45$ \\
\hline Total bilirubin $(\mu \mathrm{mol} / 1)$ & $1.11 \pm 1.64$ \\
\hline Albumin (g/dl) & $4.49 \pm 0.45$ \\
\hline INR & $1.08 \pm 0.31$ \\
\hline $\operatorname{PLT}\left(\times 10^{3} / \mathrm{ml}\right)$ & $232.79 \pm 72.24$ \\
\hline
\end{tabular}

${ }^{a}$ Standard deviation

b Metabolic syndrome-Adult Treatment Panel III (ATP III) criteria: abdominal obesity, waist circumference $>102 \mathrm{~cm}$ (men) or $>88 \mathrm{~cm}$ (women); hyperglycemia, fasting blood glucose $\geq 110 \mathrm{mg} / \mathrm{dl}$ or previously diagnosed type 2 diabetes; hypertriglyceridemia, triglycerides $\geq 150 \mathrm{mg} / \mathrm{dl}$ or current treatment for this abnormality; hypertension, blood pressure $\geq 130 / \geq 85 \mathrm{mmHg}$ or treatment for previously diagnosed hypertension); and low HDL cholesterol, $<40 \mathrm{mg} / \mathrm{dl}$ (men) or $<50 \mathrm{mg} / \mathrm{dl}$ (women) or specific treatment for this abnormality). Patients meeting $>3$ of these criteria were considered to have the metabolic syndrome

univariate analysis, cases and controls, however, differed on their eating habits, as greater proportion of cases reported to consume more than 2 portions/day of fruit $(p<0.001)$ and more than once/week portion of grilled meat or fish $(p<0.001)$ (Table 2).

Results of the multivariable analysis including the entire population under study are reported in Table 3. We observed protective effect of age (OR 0.92; $95 \%$ CI $0.91-0.94$ ), gender (OR for females $=0.51 ; 95 \%$ CI $0.31-0.83$ ), and moderate drinking habits (OR 0.59 for less than $30 \mathrm{~g}$ /day among males and 20/day among females
Table 2 Demographic and anthropometric data, and lifestyle and candidate gene factors among 234 NAFLD cases and 349 controls

\begin{tabular}{|c|c|c|c|}
\hline & Controls & Cases & $p$ value \\
\hline \multicolumn{4}{|l|}{ Demographics and lifestyle } \\
\hline Age & $62.06 \pm 13.98$ & $44.94 \pm 14.11$ & $<0.001$ \\
\hline \multicolumn{4}{|l|}{ Sex } \\
\hline Male & $220(61 \%)$ & $196(67 \%)$ & 0.15 \\
\hline Female & $139(39 \%)$ & $98(33 \%)$ & \\
\hline BMI $\left(\mathrm{kg} / \mathrm{m}^{2}\right)$ & $26.91 \pm 5.91$ & $28.89 \pm 5.25$ & 0.008 \\
\hline \multicolumn{4}{|l|}{ Smoker } \\
\hline Never & $194(54 \%)$ & $165(56 \%)$ & 0.66 \\
\hline Ever & $159(44 \%)$ & $126(43 \%)$ & \\
\hline \multicolumn{4}{|l|}{ Alcohol consumption } \\
\hline Never drinkers & $170(47 \%)$ & $160(54 \%)$ & 0.07 \\
\hline $\begin{array}{l}\text { Males: }<30 \mathrm{~g} / \text { females: } \\
\quad<20 \mathrm{~g}\end{array}$ & $182(51 \%)$ & $129(44 \%)$ & \\
\hline \multicolumn{4}{|l|}{ Fruit intake } \\
\hline $0-2$ per day & $208(58 \%)$ & $120(41 \%)$ & $<0.001$ \\
\hline$>2$ per day & $135(38 \%)$ & $161(55 \%)$ & \\
\hline \multicolumn{4}{|l|}{ Grilled meat or fish intake } \\
\hline $0-1$ per week & $142(40 \%)$ & $88(30 \%)$ & $<0.001$ \\
\hline$>1$ per week & $165(46 \%)$ & $192(65 \%)$ & \\
\hline \multicolumn{4}{|l|}{ Candidate genes } \\
\hline \multicolumn{4}{|l|}{ GSTM1 } \\
\hline Present & $172(48 \%)$ & $147(50 \%)$ & 0.54 \\
\hline Null & $187(52 \%)$ & $145(49 \%)$ & \\
\hline \multicolumn{4}{|l|}{ GSTT1 } \\
\hline Present & $276(77 \%)$ & $217(74 \%)$ & 0.45 \\
\hline Null & $83(23 \%)$ & $75(26 \%)$ & \\
\hline \multicolumn{4}{|l|}{ CYP1A1 } \\
\hline$C Y P 1 A 1 * 1 / * 1$ & $278(77 \%)$ & $231(79 \%)$ & 0.67 \\
\hline CYP $1 A 1 * 2 A$ carriers & $81(23 \%)$ & $62(21 \%)$ & \\
\hline \multicolumn{4}{|l|}{ CYP2E1PstI } \\
\hline$C Y P 2 E 1 * 1 A / 1 A$ & $331(92 \%)$ & $277(94 \%)$ & 0.17 \\
\hline$C Y P 2 E 1 * 5 B$ carriers & $28(8 \%)$ & $15(5 \%)$ & \\
\hline \multicolumn{4}{|l|}{ CYP2E1DraI } \\
\hline$C Y P 2 E 1 * 1 A / 1 A$ & $323(90 \%)$ & $271(92 \%)$ & 0.52 \\
\hline$C Y P 2 E 1 * 6$ carriers & $29(8 \%)$ & $20(7 \%)$ & \\
\hline \multicolumn{4}{|l|}{ SULT1A1 } \\
\hline$S U L T 1 A 1 * 1 / * 1$ & $224(62 \%)$ & $155(53 \%)$ & 0.02 \\
\hline SULT1A1 $* 2$ carriers & $134(37 \%)$ & $136(46 \%)$ & \\
\hline
\end{tabular}

with respect to never drinkers; $95 \%$ CI 0.37-0.94) toward the risk of NAFLD. Increased odds of NAFLD were observed for greater consumption of fruit ( $>2 /$ day: OR 3.75; $95 \%$ CI 2.34-6.03) and consumption of grilled meat or fish $>1$ /week (OR 2.38; $95 \%$ CI 1.49-3.81) (Table 3). From the multivariable analysis, the SNPs of the selected genes were not found to be associated with the risk of NAFLD (Table 3). 
Table 3 Adjusted a $\mathrm{OR}$ and $95 \% \mathrm{CI}$ for NAFLD risk according to selected variables (234 cases and 349 controls)

\begin{tabular}{|c|c|c|}
\hline & OR $[95 \% \mathrm{CI}]$ & $p$ value \\
\hline \multicolumn{3}{|l|}{ Main predictors } \\
\hline Age & $0.92[0.91 ; 0.94]$ & $<0.001$ \\
\hline \multicolumn{3}{|l|}{ Sex } \\
\hline Male & 1.00 & 0.007 \\
\hline Female & $0.51[0.31 ; 0.83]$ & \\
\hline \multicolumn{3}{|l|}{ Alcohol drinkers } \\
\hline Never drinkers & 1.00 & 0.028 \\
\hline Males: $<30 \mathrm{~g} /$ females: $<20 \mathrm{~g}$ & $0.59[0.37 ; 0.94]$ & \\
\hline \multicolumn{3}{|l|}{ Fruit intake } \\
\hline $0-2$ per day & 1.00 & $<0.001$ \\
\hline$>2$ per day & $3.75[2.34 ; 6.03]$ & \\
\hline \multicolumn{3}{|l|}{ Grilled meat or fish intake } \\
\hline 0-1 per week & 1.00 & $<0.001$ \\
\hline$>1$ per week & $2.38[1.49 ; 3.81]$ & \\
\hline \multicolumn{3}{|l|}{ Additional factors } \\
\hline \multicolumn{3}{|l|}{ Smoker } \\
\hline Never & 1.00 & 0.14 \\
\hline Ever & $0.7[0.44 ; 1.12]$ & \\
\hline \multicolumn{3}{|l|}{ GSTM1 } \\
\hline Present & 1.00 & 0.81 \\
\hline Null & $0.95[0.61 ; 1.48]$ & \\
\hline \multicolumn{3}{|l|}{ GSTT1 } \\
\hline Present & 1.00 & 0.16 \\
\hline Null & $1.45[0.86 ; 2.43]$ & \\
\hline \multicolumn{3}{|l|}{ CYP1A1 } \\
\hline$C Y P 1 A 1 * 1 / * 1$ & 1.00 & 0.74 \\
\hline CYP1A $1 * 2 A$ carriers & $1.09[0.65 ; 1.85]$ & \\
\hline \multicolumn{3}{|l|}{ CYP2E1PstI } \\
\hline$C Y P 2 E 1 * 1 A / 1 A$ & 1.00 & 0.31 \\
\hline$C Y P 2 E 1 * 5 B$ carriers & $0.63[0.26 ; 1.53]$ & \\
\hline \multicolumn{3}{|l|}{ CYP2E1DraI } \\
\hline$C Y P 2 E 1 * 1 A / 1 A$ & 1.00 & 0.58 \\
\hline CYP $2 E 1 * 6$ carriers & $1.28[0.53 ; 3.06]$ & \\
\hline \multicolumn{3}{|l|}{ SULT1A1 } \\
\hline SULT1A $1 * 1 / * 1$ & 1.00 & 0.54 \\
\hline SULT1A1 $* 2$ carriers & $1.15[0.74 ; 1.80]$ & \\
\hline
\end{tabular}

${ }^{a}$ Estimates adjusted for age, sex, drinking habits, fruit, and grilled meat and fish

The result of two-way interactions between alcohol consumption, fruit intake, grilled meat and fish, and candidate genes in the entire population is reported in Table 4. Statistically significant interactions were reported for fruit intake and GSTM1, GSTT1, CYPIA1 and CYP2E1 Dral, and SULT1Al genes, as the risky effect of high fruit intake on NAFLD was additionally increased among subjects carriers of one of the aforementioned gene variants (Table 4). Lastly, significant interaction was also reported for
CYP2E15B and alcohol intake, and GSTM1, GSTT1, CYPIA1, and SULTIIAI and grilled meat or fish intake. In testing for the effects of gene-gene interaction, a significant interaction was reported for CYP2E $1_{P s t \mathrm{I}}$ and GSTM1, with a reduced risk of NAFLD (OR $0.21 ; 95 \% \mathrm{CI}$ 0.05-0.93, data not shown) for those contemporarily carrying the two unfavorable gene variants.

Table 5 reports the results of the multivariable analysis conducted in the subgroup of 82 cases and 198 controls. Beside confirming the effects of age and alcohol on the risk of NAFLD, the subgroup analysis showed that a moderate/ high consumption of fat and/or grilled food and a high consumption of white meat increase the risk of NAFLD (OR 3.25; $95 \%$ CI 1.64-6.42, and OR 2.37; $95 \%$ CI 1.23-4.58, respectively) (Table 5). Concerning physical activity, performing at least one activity per week halves the risk of NAFLD, with an OR of 0.45 for those walking or performing competitive sport or house working or gardening, and an OR of 0.36 for those cycling or gymnastics (Table 5).

\section{Discussion}

Our hospital-based case control study including 294 NAFLD cases and 359 controls evaluated the effect of selected polymorphisms in GSTM1, GSTT1, SULT1A1, CYP2E1 and $1 A l$ genes, as well as their interaction with lifestyle and dietary habits in NAFLD etiology in an Italian population. Results show that young adults and males are at higher risk of NAFLD, as well as those with a high consumption of fruit and grilled meat/fish. A moderate alcohol consumption, however, is a protective factor toward the risk of NAFLD. Subgroup analysis showed that a combination of moderate/high fat intake and/or grilled food intake is associated with increased risk of NAFLD, as well as high white meat intake. Additionally, the subgroup analysis reported that performing any physical activity at least once per week halves the risk of NAFLD.

A recent review (Zelber-Sagi et al. 2011) summarized the effect of nutrition and physical activity in the etiology of NAFLD. The reports show that most of the observational studies conducted support an increased risk of disease associated with high fat and sugar intake (the so called "Western" dietary pattern) (Oddy et al. 2013) and a decreased risk associated with physical activity engagement (Zelber-Sagi et al. 2011).

Our study shows an increased odd of NAFLD among males and young adults which is supporting some recent findings (Adams et al. 2005; Oddy et al. 2013), while the protective effect of moderate alcohol drinking is still under debate. Moderate alcohol drinking might have a protective role on the risk of developing NAFLD in view of the 


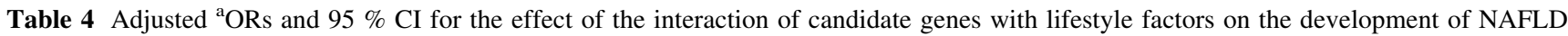
(234 cases and 349 controls)

\begin{tabular}{|c|c|c|c|c|c|c|}
\hline & \multicolumn{2}{|l|}{ Alcohol intake } & \multicolumn{2}{|l|}{ Fruit intake } & \multicolumn{2}{|c|}{ Grilled meat or fish intake } \\
\hline & Never drinkers & $\begin{array}{l}\text { Males: }<30 \mathrm{~g} \\
\text { Females: }<20 \mathrm{~g}\end{array}$ & $0-2 /$ day & $>2 /$ day & $0-1 /$ week & $>1 /$ week \\
\hline \multicolumn{7}{|l|}{ GSTM1 } \\
\hline Present & 1.00 & $\begin{array}{l}0.56 \\
{[0.29 ; 1.07]}\end{array}$ & 1.00 & $\begin{array}{l}3.06 \\
{[1.60 ; 5.84]}\end{array}$ & 1.00 & $\begin{array}{l}1.83 \\
{[0.96 ; 3.46]}\end{array}$ \\
\hline Null & $\begin{array}{l}0.89 \\
{[0.48 ; 1.66]}\end{array}$ & $\begin{array}{l}0.56 \\
{[0.29 ; 1.07]} \\
p^{\mathrm{b}}=0.081\end{array}$ & $\begin{array}{l}0.77 \\
{[0.41 ; 1.45]}\end{array}$ & $\begin{array}{l}3.55 \\
{[1.88 ; 6.68]} \\
p<0.001\end{array}$ & $\begin{array}{l}0.68 \\
{[0.34 ; 1.36]}\end{array}$ & $\begin{array}{l}2.18 \\
{[1.18 ; 4.03]} \\
p=0.013\end{array}$ \\
\hline \multicolumn{7}{|l|}{ GSTT1 } \\
\hline Present & 1.00 & $\begin{array}{l}0.59 \\
{[0.35 ; 1.01]}\end{array}$ & 1.00 & $\begin{array}{l}4.23 \\
{[2.46 ; 7.29]}\end{array}$ & 1.00 & $\begin{array}{l}2.65 \\
{[1.54 ; 4.58]}\end{array}$ \\
\hline Null & $\begin{array}{l}1.47 \\
{[0.71 ; 3.06]}\end{array}$ & $\begin{array}{l}0.85 \\
{[0.41 ; 1.76]} \\
p=0.655\end{array}$ & $\begin{array}{l}1.83 \\
{[0.89 ; 3.76]} \\
{[-0.829 ; 0.732]}\end{array}$ & $\begin{array}{l}4.82 \\
{[2.26 ; 10.32]} \\
p<0.001\end{array}$ & $\begin{array}{l}1.82 \\
{[0.82 ; 4.03]} \\
{[-0.856 ; 0.726]}\end{array}$ & $\begin{array}{l}3.26 \\
{[1.57 ; 6.79]} \\
p=0.002\end{array}$ \\
\hline \multicolumn{7}{|l|}{ CYP1A1 } \\
\hline$C Y P 1 A 1 * 1 / * 1$ & 1.00 & $\begin{array}{l}0.55 \\
{[0.32 ; 0.94]}\end{array}$ & 1.00 & $\begin{array}{l}3.06 \\
{[1.80 ; 5.20]}\end{array}$ & 1.00 & $\begin{array}{l}2.37 \\
{[1.39 ; 4.04]}\end{array}$ \\
\hline CYP1A $1 * 2 A$ carriers & $\begin{array}{l}0.92 \\
{[0.43 ; 1.99]}\end{array}$ & $\begin{array}{l}0.70 \\
{[0.34 ; 1.43]} \\
p=0.326\end{array}$ & $\begin{array}{l}0.72 \\
{[0.34 ; 1.53]}\end{array}$ & $\begin{array}{l}5.17 \\
{[2.37 ; 11.27]} \\
p<0.001\end{array}$ & $\begin{array}{l}1.10 \\
{[0.48 ; 2.51]} \\
{[-0.686 ; 0.779]}\end{array}$ & $\begin{array}{l}2.59 \\
{[1.25 ; 5.36]} \\
p=0.011\end{array}$ \\
\hline \multicolumn{7}{|l|}{$C Y P 2 E 1_{P s t \mathrm{I}}$} \\
\hline$C Y P 2 E 1 * 1 A / 1 A$ & 1.00 & $\begin{array}{l}0.62 \\
{[0.38 ; 1.00]}\end{array}$ & 1.00 & $\begin{array}{l}3.82 \\
{[2.34 ; 6.25]}\end{array}$ & 1.00 & $\begin{array}{l}2.23 \\
{[1.37 ; 3.62]}\end{array}$ \\
\hline CYP $2 E 1 * 5 B$ carriers & $\begin{array}{l}0.92 \\
{[0.28 ; 3.08]}\end{array}$ & $\begin{array}{l}0.25 \\
{[0.06 ; 0.98]} \\
p=0.046\end{array}$ & $\begin{array}{l}0.68 \\
{[0.18 ; 2.58]}\end{array}$ & $\begin{array}{l}2.31 \\
{[0.71 ; 7.47]} \\
p=0.163\end{array}$ & $\begin{array}{l}0.41 \\
{[0.10 ; 1.71]}\end{array}$ & $\begin{array}{l}1.93 \\
{[0.59 ; 6.28]} \\
p=0.273\end{array}$ \\
\hline \multicolumn{7}{|l|}{$C Y P 2 E 1_{\text {DraI }}$} \\
\hline$C Y P 2 E 1 * 1 A / 1 A$ & 1.00 & $\begin{array}{l}0.56 \\
{[0.34 ; 0.92]}\end{array}$ & 1.00 & $\begin{array}{l}3.53 \\
{[2.14 ; 5.82]}\end{array}$ & 1.00 & $\begin{array}{l}2.38 \\
{[1.45 ; 3.91]}\end{array}$ \\
\hline CYP $2 E 1 * 6$ carriers & $\begin{array}{l}1.09 \\
{[0.36 ; 3.32]}\end{array}$ & $\begin{array}{l}0.92 \\
{[0.22 ; 3.80]} \\
p=0.911\end{array}$ & $\begin{array}{l}0.52 \\
{[0.13 ; 2.05]}\end{array}$ & $\begin{array}{l}11.34 \\
{[2.70 ; 47.55]} \\
p=0.001\end{array}$ & $\begin{array}{l}2.32 \\
{[0.37 ; 14.67]} \\
{[-2.547 ; 1.682]}\end{array}$ & $\begin{array}{l}2.58 \\
{[0.95 ; 7.04]} \\
p=0.063\end{array}$ \\
\hline \multicolumn{7}{|l|}{ SULT1A1 } \\
\hline SULT1A1*1/*1 & 1.00 & $\begin{array}{l}0.55 \\
{[0.30 ; 1.01]}\end{array}$ & 1.00 & $\begin{array}{l}4.05 \\
{[2.17 ; 7.53]}\end{array}$ & 1.00 & $\begin{array}{l}2.07 \\
{[1.12 ; 3.83]}\end{array}$ \\
\hline SULT1A1*2carriers & $\begin{array}{l}1.04 \\
{[0.56 ; 1.94]}\end{array}$ & $\begin{array}{l}0.71 \\
{[0.36 ; 1.38]} \\
p=0.314\end{array}$ & $\begin{array}{l}1.28 \\
{[0.68 ; 2.42]} \\
{[-0.697 ; 0.624]}\end{array}$ & $\begin{array}{l}4.18 \\
{[2.20 ; 7.94]} \\
p<0.001\end{array}$ & $\begin{array}{l}0.97 \\
{[0.48 ; 1.95]}\end{array}$ & $\begin{array}{l}2.69 \\
{[1.42 ; 5.10]} \\
p=0.002\end{array}$ \\
\hline
\end{tabular}

${ }^{a}$ Estimates adjusted for age, sex, drinking habits, fruit, and grilled meat and fish

${ }^{\mathrm{b}} p$ for the interaction from logistic regression analysis

associated insulin-sensitizing effect (Dunn et al. 2008) or through the beneficial effect of high-density lipoprotein (HDL) cholesterol increased levels as for cardiovascular disease (CVD) (Djousse et al. 2009). Additional studies, however (Abdelmalek et al. 2010; Abid et al. 2009), suggested that a high intake of soft drinks which are rich of fructose, might have a detrimental effect on the risk of NAFLD (Miele et al. 2009). In our study, the information on alcohol, however, was limited to wine and spirits consumption, thus did not include information on soft drinks consumption. This might partly explain the absence of any risky effect associated with moderate alcohol intake, in 
Table 5 Adjusted ${ }^{a} \mathrm{OR}$ and $95 \%$ CI for the risk of NAFLD—a subgroup analysis (82 cases and 198 controls)

\begin{tabular}{|c|c|c|c|c|}
\hline & Cases & Controls & OR $[95 \% \mathrm{CI}]$ & $p$ value \\
\hline \multicolumn{5}{|l|}{ Main predictors } \\
\hline Age & $57.07 \pm 15.45$ & $45.85 \pm 14.09$ & $0.95[0.93 ; 0.98]$ & $<0.001$ \\
\hline \multicolumn{5}{|l|}{ Alcohol consumption } \\
\hline Never drinkers & $29(35 \%)$ & $104(52 \%)$ & 1 & \\
\hline Males: $<30 \mathrm{~g} /$ females: $<20 \mathrm{~g}$ & $47(57 \%)$ & $90(45 \%)$ & $0.39[0.2 ; 0.77]$ & 0.006 \\
\hline \multicolumn{5}{|l|}{ Sausages-red meat-grilled meat/fish ${ }^{\mathrm{b}}$} \\
\hline Low-grilled food and low-moderate fat intake & $51(62 \%)$ & $69(35 \%)$ & 1 & \\
\hline Moderate-high fat intake and/or high grilled food & $24(29 \%)$ & $123(62 \%)$ & $3.25[1.64 ; 6.42]$ & 0.001 \\
\hline \multicolumn{5}{|l|}{ White meat } \\
\hline$<8$ times/month & $43(52 \%)$ & $63(32 \%)$ & 1 & \\
\hline$\geq 8$ times/month & $34(41 \%)$ & $133(67 \%)$ & $2.37[1.23 ; 4.58]$ & 0.010 \\
\hline \multicolumn{5}{|l|}{ Walking-competitive sport-housework-gardening } \\
\hline$\leq 1$ activity & $41(50 \%)$ & $141(71 \%)$ & 1 & \\
\hline$>1$ activity/week & $34(41 \%)$ & $51(26 \%)$ & $0.45[0.23 ; 0.88]$ & 0.02 \\
\hline \multicolumn{5}{|l|}{ Cycling-gymnastics } \\
\hline No activity & $58(71 \%)$ & $155(78 \%)$ & 1 & \\
\hline$\geq 1$ activity/week & $17(21 \%)$ & $41(21 \%)$ & $0.36[0.15 ; 0.85]$ & 0.019 \\
\hline \multicolumn{5}{|l|}{ Additional factors } \\
\hline \multicolumn{5}{|l|}{ Sex } \\
\hline Female & $30(37 \%)$ & $63(32 \%)$ & 1 & \\
\hline Male & $52(63 \%)$ & $135(68 \%)$ & $1.47[0.69 ; 3.16]$ & 0.320 \\
\hline \multicolumn{5}{|l|}{ Smoker } \\
\hline Never & $31(38 \%)$ & $108(54 \%)$ & 1 & \\
\hline Ever & $46(56 \%)$ & $88(44 \%)$ & $0.61[0.3 ; 1.24]$ & 0.174 \\
\hline \multicolumn{5}{|l|}{ Fruit-vegetables-pulses ${ }^{\mathrm{c}}$} \\
\hline Low-moderate intake & $39(48 \%)$ & $137(69 \%)$ & 1 & \\
\hline High intake & $38(46 \%)$ & $56(28 \%)$ & $0.58[0.29 ; 1.15]$ & 0.120 \\
\hline \multicolumn{5}{|l|}{ Eat between meals } \\
\hline No & $58(71 \%)$ & $123(62 \%)$ & 1 & \\
\hline Yes & $19(23 \%)$ & $70(35 \%)$ & $1.16[0.57 ; 2.35]$ & 0.690 \\
\hline
\end{tabular}

${ }^{a}$ Estimates adjusted for age, drinking habits, additional use of salt, meat intake, and physical activity

b Sausage, red meat and grilled meat/fish (low-grilled food: $\leq 1$ portions/month; high grilled food: $>1$ portions/month; low fat from sausage and red meat: $<3$ portions of sausages/month and $\leq 13$ portions of red meat/month ( $\leq 4$ portions/week); moderate fat intake: $\geq 3$ portions of sausages/ month or $>13$ portions of red meat/month ( $>4$ portions/week); high fat intake: $\geq 3$ portions of sausages/month and $>13$ portions of red meat/ month ( $>4$ portions/week))

${ }^{c}$ Fruit, vegetables and pulses (low intake: $<5$ portions of pulses/month and $\leq 9$ portions of fruit/week and $\leq 9$ portions of vegetables/week, or $<5$ portions of pulses/month and $>9$ portions of fruit/week and $>9$ portions of vegetables/week; moderate intake: $<5$ portions of pulses/month and $>9$ portions of fruit/week and $>9$ portions of vegetables/week, or $\geq 5$ portions of pulses/month and $\leq 9$ portions of fruit/week and $\leq 9$ portions of vegetables/week; high intake: $\geq 5$ portions of pulses/month and $>9$ portions of fruit/week and/or $>9$ portions of vegetables/week (or vice versa))

view of the different fructose concentration among the aforementioned beverages.

Concerning nutrients intake, our data show that high fruit intake increases the risk of NAFLD, which has already been reported, and as already mentioned likely due to the potential role played by fructose in liver de novo lipogenesis and hepatic inflammation (Shi et al. 2012; Lim et al. 2010). Additionally, we report that a high consumption of grilled meat/fish alone, or in combination with moderate/ high fat consumption, and a high consumption of white meat increases the risk of NAFLD. However, we were unable to demonstrate any beneficial effect of vegetable consumption on disease risk. As mentioned, several reports summarized in a recent review (Zelber-Sagi et al. 2011) agree on the effect of unhealthy dietary pattern rich in fat and poor in vegetables, on the risk of NAFLD. Our results confirm such observation, though we were unable to estimate the effect of vegetables and pulses independently of 
the effect of fruit. This might have led to an underestimation of the true beneficial effect of such nutrients on disease risk. As for the high consumption of grilled meat/ fish associated with an increased odd of disease, to our knowledge, there are no data currently available correlating the presence of aromatic hydrocarbons generated by grilled meat and fish and the risk of NAFLD.

Our study reports that performing any kind of physical activity at least one time per week exerts a protective role on the risk of NAFLD. The effect is stronger for those engaging cycling and gymnastic. The beneficial effects of physical activity in the treatment for NAFLD are already documented, as regular physical activity improves liver enzyme activities and reduces the overall oxidative stress (Zelber-Sagi et al. 2008, 2011; Church et al. 2006).

We were unable to demonstrate a direct effect on the risk of NAFLD related to SNPs of oxidative-stress-associated genes. The candidate genes were selected on the background hypothesis that the onset and progression of fatty liver may be due to a contribution of oxidative stress (Sumida et al. 2013). Namely, glutathione- $S$-transferases (GSTs) have a pivotal role as antioxidant defense mechanisms, and in conjunction with SULT and CYP2E1, products act by inactivating xenobiotics and products of oxidative stress (Bolt and Thier 2006). Moreover, GSTM 1 and GSTT1 null genotypes are associated with type 2 diabetes and its complications which (Doney et al. 2005) are closely related to NAFLD with several reports underlining the role of GSTT on liver damage (Targher et al. 2010; Huang et al. 2007; Ueda et al. 2007; Oniki et al. 2007). No one study so far ever addressed the effect of SULT1A1 and CYP1A1 polymorphisms on NAFLD, while GSTT1 but not GSTT1 genetic polymorphisms have been associated with NAFLD in a sample of the Iranian population (Hashemi et al. 2012). Polymorphisms of CYP2E1 and insulin resistance are associated with higher levels and activity of the enzyme in obese patients with NASH, which have been related to increased risk of liver damage. Therefore, the occurrence of genetic polymorphisms increasing CYP2E1 expression in the etiology of NASH can in principle represent susceptibility factors to acquire insulin resistance mediated by oxidative stress (Varela et al. 2008). In our population, however, we were unable to show association between the aforementioned genetic variants and the risk of NAFLD.

From the gene, lifestyle, and nutrient interaction analysis, we report that significant interactions occurred between fruit intake and GSTM1, GSTT1, CYP1Al and CYP2E $1_{\text {Dral }}$, and SULTIAI genes, as the risky effect of high fruit intake on NAFLD was additionally increased among subjects carriers of one of the aforementioned gene variants. Additionally, a significant interaction was also reported for CYP2E15B and alcohol intake, and GSTM1,
GSTT1, CYP1A1, and SULTIIAl and grilled meat or fish intake. It is reasonable to postulate that in subjects with enzyme null variants of GST or polymorphisms associated with an increased activity of the cytochromes, in the presence of exposure to aromatic hydrocarbons, there is an imbalance in the liver function which favors the development of damage.

To our knowledge, this study is the first study testing the effects of the selected gene-gene interaction on the risk of NAFLD. The results show a significant interaction between $C Y P 2 E 1_{P s t I}$ and $G S T M 1$ genes, with a $80 \%$ reduced risk of NAFLD for those contemporarily carrying the two unfavorable gene variants. No one reported a protective effect of the two unfavorable gene variants on the risk of developing a disease so far, while their combination has been related to increased susceptibility to alcoholic liver cirrhosis (Khan et al. 2009) and Head and Neck Cancer (Ruwali et al. 2009). As we may have been underpowered due to sample size in the interaction analysis, our result requires confirmation from independent and larger studies.

Some limitations of the study should be considered in interpreting our results. Our sample size though large limits the possibility to detect significant gene-lifestyle interaction, thus we need to increase the sample size in order to confirm our results, also because the absence of liver biopsy for all the participating subjects cannot allow us to draw any conclusion of the interaction on liver histological liver damage. Secondly, as in all case-control studies, information bias may exist, leading to biased ORs due to exposure misclassification of the lifestyle and nutrients exposure. Thirdly, we were unable to explore the effect of certain dietary patterns in the entire sample size and unable to assess the independent effect of vegetables and pulses on the risk of NAFLD. Lastly, even though the measurement of oxidative stress biomarkers was beyond the aim of this study, it would be worth to measure such levels in future investigations.

Besides the acknowledged limitations, however, our report is the first examining the effect of genetic variants involved in the oxidative stress and nutrition on NAFLD etiology. Even though replication is demanded, our results show that the genetic background among genes involved in metabolism of liver detoxification might modify the effect of fruit and grilled meat/fish intake that already affect per se the risk of NAFLD. Additionally, our report confirms the excess risk of NAFLD associated with high fruit and fat intake, while for the first time, we reported a significant association with high intake of grilled food and disease risk. Lastly, the beneficial effect of any kind of physical activity is confirmatory of previous evidences and strengthens the knowledge of the benefits of physical activity on NAFLD beyond encouraging weight reduction. 
Acknowledgments Supported by grants: MIUR-Catholic University Research Grants Linea D1 (A.Gr.); Cofin MIUR-Catholic University "GiovaniRicercatori 2002" and Istituto Toniolo Research Prize (L.M.); Livio Patrizi Young Investigator Grant by Italian Society of Internal Medicine (C.C.), Erasmus Mundus Western Balkans(ERAWEB) Fellowship (B.N.)

Conflict of interest Luca Miele, Valentina Dall'Armi, Consuelo Cefalo, Bojan Nedovic, Dario Arzani, Rosarita Amore, Gianlodovico Rapaccini, Antonio Gasbarrini, Walter Ricciardi, Antonio Grieco, and Stefania Boccia declare that they have no conflict of interest.

Ethical Standards All procedures followed were in accordance with the ethical standards of the responsible committee on human experimentation (institutional and national) and with the Helsinki Declaration. Informed consent was obtained from all patients for being included in the study.

\section{References}

Abdelmalek MF, Suzuki A, Guy C, Unalp-Arida A, Colvin R, Johnson RJ, Diehl AM, Nonalcoholic Steatohepatitis Clinical Research Network (2010) Increased fructose consumption is associated with fibrosis severity in patients with nonalcoholic fatty liver disease. Hepatology 51:1961-1971

Abid A, Taha O, Nseir W, Farah R, Grosovski M, Assy N (2009) Soft drink consumption is associated with fatty liver disease independent of metabolic syndrome. J Hepatol 51:918-924

Adams LA, Lymp JF, St Sauver J, Sanderson SO, Lindor KD, Feldstein A, Angulo P (2005) The natural history of nonalcoholic fatty liver disease: a population-based cohort study. Gastroenterology 129:113-121

Arand M, Muhlbauer R, Hengstler J, Jager E, Fuchs J, Winkler L, Oesch F (1996) A multiplex polymerase chain reaction protocol for the simultaneous analysis of the glutathione S-transferase GSTM1 and GSTT1 polymorphisms. Anal Biochem 236:184-186

Bell LN, Molleston JP, Morton MJ, Klipsch A, Saxena R, Vuppalanchi R, Chalasani N (2011) Hepatic lipid peroxidation and cytochrome $\mathrm{P}-4502 \mathrm{E} 1$ in pediatric nonalcoholic fatty liver disease and its subtypes. J Clin Gastroenterol 45:800-807

Bolt HM, Thier R (2006) Relevance of the deletion polymorphisms of the glutathione S-transferases GSTT1 and GSTM1 in pharmacology and toxicology. Curr Drug Metab 7:613-628

Chalasani N, Younossi Z, Lavine JE, Diehl AM, Brunt EM, Cusi K, Charlton M, Sanyal AJ (2012) The diagnosis and management of non-alcoholic fatty liver disease: practice guideline by the American Association for the Study of Liver Diseases, American College of Gastroenterology, and the American Gastroenterological Association. Am J Gastroenterol 107:811-826

Church TS, Kuk JL, Ross R, Priest EL, Biltoft E, Blair SN (2006) Association of cardiorespiratory fitness, body mass index, and waist circumference to nonalcoholic fatty liver disease. Gastroenterology 130:2023-2030

Cordell HJ, Clayton DG (2005) Genetic association studies. Lancet 366:1121-1131

Coughtrie MW, Gilissen RA, Shek B, Strange RC, Fryer AA, Jones PW, Bamber DE (1999) Phenol sulphotransferase SULT1A1 polymorphism: molecular diagnosis and allele frequencies in Caucasian and African populations. Biochem J 337:45-49

Daly AK, Ballestri S, Carulli L, Loria P, Day CP (2011) Genetic determinants of susceptibility and severity in nonalcoholic fatty liver disease. Expert Rev Gastroenterol Hepatol 5:253-263
De Feo E, Cefalo C, Arzani D, Amore R, Landolfi R, Grieco A, Ricciardi W, Miele L, Boccia S (2012) A case-control study on the effects of the apolipoprotein $\mathrm{E}$ genotypes in nonalcoholic fatty liver disease. Mol Biol Rep 39:7381-7388

Djousse L, Himali JJ, Beiser A, Kelly-Hayes M, Wolf PA (2009) Apolipoprotein e, alcohol consumption, and risk of ischemic stroke: the Framingham Heart Study revisited. J Stroke Cerebrovasc Dis 18:384-388

Doney AS, Lee S, Leese GP, Morris AD, Palmer CN (2005) Increased cardiovascular morbidity and mortality in type 2 diabetes is associated with the glutathione $\mathrm{S}$ transferase theta-null genotype: a Go-DARTS study. Circulation 111:2927-2934

Dunn W, Xu R, Schwimmer JB (2008) Modest wine drinking and decreased prevalence of suspected nonalcoholic fatty liver disease. Hepatology 47:1947-1954

Fisher CD, Lickteig AJ, Augustine LM, Ranger-Moore J, Jackson JP, Ferguson SS, Cherrington NJ (2009) Hepatic cytochrome P450 enzyme alterations in humans with progressive stages of nonalcoholic fatty liver disease. Drug Metab Dispos 37:2087-2094

Hardwick RN, Ferreira DW, More VR, Lake AD, Lu Z, Manautou JE, Slitt AL, Cherrington NJ (2013) Altered UDP-glucuronosyltransferase and sulfotransferase expression and function during progressive stages of human nonalcoholic fatty liver disease. Drug Metab Dispos 41:554-561

Hashemi M, Eskandari-Nasab E, Fazaeli A, Bahari A, Hashemzehi NA, Shafieipour S, Taheri M, Moazeni-Roodi A, Zakeri Z, Bakhshipour A, Ghavami S (2012) Association of genetic polymorphisms of glutathione-S-transferase genes (GSTT1, GSTM1, and GSTP1) and susceptibility to nonalcoholic fatty liver disease in Zahedan, Southeast Iran. DNA Cell Biol $31: 672-677$

Hijona E, Hijona L, Arenas JI, Bujanda L (2010) Inflammatory mediators of hepatic steatosis. Mediators Inflamm 2010:837419

Hori M, Oniki K, Nakagawa T, Takata K, Mihara S, Marubayashi T, Nakagawa K (2009) Association between combinations of glutathione-S-transferase M1, T1 and P1 genotypes and nonalcoholic fatty liver disease. Liver Int 29:164-168

Huang YS, Su WJ, Huang YH, Chen CY, Chang FY, Lin HC, Lee SD (2007) Genetic polymorphisms of manganese superoxide dismutase, $\mathrm{NAD}(\mathrm{P}) \mathrm{H}$ : quinone oxidoreductase, glutathione S-transferase M1 and T1, and the susceptibility to drug-induced liver injury. J Hepatol 47:128-134

Khan AJ, Ruwali M, Choudhuri G, Mathur N, Husain Q, Parmar D (2009) Polymorphism in cytochrome P450 2E1 and interaction with other genetic risk factors and susceptibility to alcoholic liver cirrhosis. Mutat Res 664(1-2):55-63

Lim JS, Mietus-Snyder M, Valente A, Schwarz JM, Lustig RH (2010) The role of fructose in the pathogenesis of NAFLD and the metabolic syndrome. Nat Rev Gastroenterol Hepatol 7:251-264

Loomba R, Sanyal AJ (2013) The global NAFLD epidemic. Nat Rev Gastroenterol Hepatol. doi:10.1038/nrgastro.2013.171

Loria P, Adinolfi LE, Bellentani S, Bugianesi E, Grieco A, Fargion S, Gasbarrini A, Loguercio C, Lonardo A, Marchesini G, Marra F, Persico M, Prati D, Baroni GS (2010) Practice guidelines for the diagnosis and management of nonalcoholic fatty liver disease. A decalogue from the Italian Association for the Study of the Liver (AISF) Expert Committee. Dig Liver Dis 42:272-282

Matthews DR, Hosker JP, Rudenski AS, Naylor BA, Treacher DF, Turner RC (1985) Homeostasis model assessment: insulin resistance and beta-cell function from fasting plasma glucose and insulin concentrations in man. Diabetologia 28:412-419

Miele L, Forgione A, Hernandez AP, Gabrieli ML, Vero V, Di Rocco P, Greco AV, Gasbarrini G, Gasbarrini A, Grieco A (2005) The natural history and risk factors for progression of non-alcoholic 
fatty liver disease and steatohepatitis. Eur Rev Med Pharmacol Sci 9:273-277

Miele L, Valenza V, La Torre G, Montalto M, Cammarota G, Ricci R, Masciana R, Forgione A, Gabrieli ML, Perotti G, Vecchio FM, Rapaccini G, Gasbarrini G, Day CP, Grieco A (2009) Increased intestinal permeability and tight junction alterations in nonalcoholic fatty liver disease. Hepatology 49:1877-1887

Oddy WH, Herbison CE, Jacoby P, Ambrosini GL, O'Sullivan TA, Ayonrinde OT, Olynyk JK, Black LJ, Beilin LJ, Mori TA, Hands BP, Adams LA (2013) The Western dietary pattern is prospectively associated with nonalcoholic fatty liver disease in adolescence. Am J Gastroenterol 108:778-785

Oniki K, Ueda K, Hori M, Mihara S, Marubayashi T, Nakagawa K (2007) Glutathione-S-transferase (GST)M1 null genotype and combined GSTM1 and GSTT1 null genotypes as a risk factor for alcoholic mild liver dysfunction. Clin Pharmacol Ther 81:634-635

Ruwali M, Khan AJ, Shah PP, Singh AP, Pant MC, Parmar D (2009) Cytochrome P450 2E1 and head and neck cancer: interaction with genetic and environmental risk factors. Environ Mol Mutagen 5(6):473-482

Sanyal AJ (2002) AGA technical review on nonalcoholic fatty liver disease. Gastroenterology 123:1705-1725

Shi L, Liu ZW, Li Y, Gong C, Zhang H, Song LJ, Huang CY, Li M (2012) The prevalence of nonalcoholic fatty liver disease and its association with lifestyle/dietary habits among university faculty and staff in Chengdu. Biomed Environ Sci 25:383-391

Solga S, Alkhuraishe AR, Clark JM, Torbenson M, Greenwald A, Diehl AM, Magnuson T (2004) Dietary composition and nonalcoholic fatty liver disease. Dig Dis Sci 49:1578-1583

Sookoian S, Pirola CJ (2011) Meta-analysis of the influence of I148M variant of patatin-like phospholipase domain containing 3 gene
(PNPLA3) on the susceptibility and histological severity of nonalcoholic fatty liver disease. Hepatology 53(6):1883-1894

Sumida Y, Niki E, Naito Y, Yoshikawa T (2013) Involvement of free radicals and oxidative stress in NAFLD/NASH. Free Radic Res 47:869-880

Tappy L, Le KA (2012) Does fructose consumption contribute to nonalcoholic fatty liver disease? Clin Res Hepatol Gastroenterol 36:554-560

Targher G, Day CP, Bonora E (2010) Risk of cardiovascular disease in patients with nonalcoholic fatty liver disease. $\mathrm{N}$ Engl $\mathrm{J}$ Med 363:1341-1350

Tilg H, Moschen AR (2010) Evolution of inflammation in nonalcoholic fatty liver disease: the multiple parallel hits hypothesis. Hepatology 52:1836-1846

Ueda K, Ishitsu T, Seo T, Ueda N, Murata T, Hori M, Nakagawa K (2007) Glutathione S-transferase M1 null genotype as a risk factor for carbamazepine-induced mild hepatotoxicity. Pharmacogenomics 8:435-442

Varela NM, Quiñones LA, Orellana M, Poniachik J, Csendes A, Smok G, Rodrigo R, Cáceres DD, Videla LA (2008) Study of cytochrome P450 2E1 and its allele variants in liver injury of nondiabetic, nonalcoholic steatohepatitis obese women. Biol Res 41:81-92

Zelber-Sagi S, Nitzan-Kaluski D, Goldsmith R, Webb M, Zvibel I, Goldiner I, Blendis L, Halpern Z, Oren R (2008) Role of leisuretime physical activity in nonalcoholic fatty liver disease: a population-based study. Hepatology 48:1791-1798

Zelber-Sagi S, Ratziu V, Oren R (2011) Nutrition and physical activity in NAFLD: an overview of the epidemiological evidence. World J Gastroenterol 17:3377-3389 